\title{
Substance P Induces the Secretion of Gelatinase A from Human Synovial Fibroblasts
}

\author{
Adelheid Hecker-Kia ${ }^{1}$, Hansjörg Kolkenbrock', Dagmar Orgel ${ }^{1}$, Bernd Zimmermann ${ }^{2}$, Martin Sparmann $^{3}$ and \\ Norbert Ulbrich ${ }^{1}$ \\ ${ }^{1}$ Deutsches Rheuma-Forschungszentrum Berlin, Berlin, Germany and Universitätsklinikum Charité, Medizinische \\ Universitätsklinik und Poliklinik III für Rheumatologie und Klinische Immunologie der Humboldt Universität zu \\ Berlin, Berlin, Germany \\ ${ }^{2}$ Institut für Anatomie, Fachbereich Humanmedizin, Universitätsklinikum Benjamin Franklin, Freie Universität \\ Berlin, Berlin, Germany \\ ${ }^{3}$ Immanuel-Krankenhaus GmbH, Rheumaklinik, Berlin, Germany
}

Summary: We investigated the secretion of the matrix metalloproteinases, interstitial collagenase (matrix metalloproteinase-1), gelatinase A (matrix metalloproteinase-2) and stromelysin-1 (matrix metalloproteinase-3) in human synovial fibroblasts after stimulation with the neuropeptide substance $P$.

Human synovial fibroblasts were stimulated with substance $P$ or interleukin-1 $\beta$ (IL-1 $\beta$ ). In the cell culture media gelatinase A, interstitial collagenase and stromelysin-1 were identified and their activities towards different substrates were determined.

Substance $\mathrm{P}$ in synovial fibroblasts induced an increase in the overall matrix metalloproteinase activity towards the dinitrophenyl-labelled peptide by $85 \%$, against an increase of $124 \%$ after stimulation with IL- $1 \beta$. In case of substance $P$ stimulation, the increase in activity reflects a significantly enhanced secretion of gelatinase $A$, whereas no significant increase of stromelysin-1 and collagenase secretion could be observed.

The matrix metalloproteinase pattern showing the highest gelatinase A secretion was obtained after stimulation with substance $P$. This pattern was very pronounced and differed very clearly from the pattern seen after IL- $1 \beta$ stimulation which caused a significant rise in collagenase and stromelysin-1 activity. We assume that distinct stimulation pathways are involved and that the neuropeptide (substance $\mathrm{P}$ ), which is always present in the inflamed joint, plays its own and separate role in proliferative processes leading to the cartilage destruction.

\section{Introduction}

During the last years the possible role of neuropeptides, especially substance $P$ in rheumatoid arthritis, has been discussed. Substance $P$ is implicated in neurogenic inflammatory processes, induction of vasodilatation, oedema and pain $(1,2)$.

High levels of substance $\mathbf{P}-$ not produced by synoviocytes, but rather of neurogenic origin - are found in rheumatoid synovial fluid (3-7). After application of substance $P$ in vitro, the release of interleukin- 1 and interleukin- 6 from monocytes as well as oxidative enzymes from macrophages are observed. Lotz et al. (8) also report on secretion of collagenolytic activity by monocytes after substance $P$ treatment.

Inconsistent reports exist whether or not proliferation of synovial fibroblasts occurs after stimulation with substance $P(5,9,10)$. It is also documented that the neuropeptide substance $P$ induces the production of prostaglandin $E_{2}$, interleukin-1 and collagenase in synovial fi- broblasts $(5,11)$. In these cells, but also in monocytes/ macrophages and leukocytes, which are all present in the inflamed joint, not only collagenase, but also members of the three subclasses of matrix metalloproteinases - collagenase, gelatinase A and stromelysin-1 - are expressed. In non-inflammatory situations these enzymes $^{1}$ ) are responsible for normal remodeling of the extracellular matrix. Their activities are strictly regulated by activation and inhibition processes. However, the key position of regulation remains to be the induction of matrix metalloproteinase expression (12), which is under the control of several cytokines, growth factors, tumour promoters and oncogenes (13). Only substances like the second messenger analogue of diacylglycerol,

\footnotetext{
1) Enzymes:

Fibroblast collagenase (Matrix metalloproteinase 1) EC 3.4.24.7

Gelatinase A (Matrix metalloproteinase 2) EC 3.4.24.24

Gelatinase B (Matrix metalloproteinase 9) EC 3.4.24.35

Stromelysin-1 (matrix metalloproteinase 3) EC 3.4.24.17

Trypsin EC 3.4.21.4
} 
phorbol-12-myristate-13-acetate, have a more uniform stimulatory effect on the expression of all matrix metalloproteinases in various tissues (13). Interleukin-1 induces selectively the production of collagenase and stromelysin-1 in synovial fibroblasts (14-16). Tumour growth factor $\beta$ on the other hand induces selectively the gelatinases A and B, while it has an inhibitory effect on collagenase and stromelysin-1 expression (13).

Considering the action of substance P, Lotz et al. (5) suggested a more general stimulatory effect on collagenase expression as part of an overall increase in protein synthesis.

Here we report on the pattern of matrix metalloproteinase expression (gelatinase $\mathrm{A}$, interstitial collagenase and stromelysin-1) after stimulation of synovial fibroblasts with substance $P$. The substance P-induced matrix metalloproteinase pattern is compared to that obtained after stimulation with interleukin-1, the central mediator of inflammation.

\section{Materials and Methods}

\section{Materials}

Synovial tissue originated from 20 patients with rheumatoid arthritis of the Rheumaklinik, Immanuel-Krankenhaus, Berlin, undergoing surgical synovectomy or total joint replacement. None of these patients had obtained any steroidal antiinflammatory therapy, but they received other therapies of various kinds.

The following materials were purchased: human recombinant IL$1 \beta$ from Biomol, Hamburg, Germany; N-(2,4)-dinitrophenyl-ProGln-Gly-Ile-Ala-Gly-Gln- $D$-Arg (dinitrophenyl-labelled peptide) from Bissendorf Biochemicals, Hannover, Germany; the fluorogenic substrates (7-methoxycoumarin-4-yl)acetyl-Pro-Leu-GlyLeu[3-(2,4-dinitrophenyl)- $L$-2,3-diaminopropionyl]-ala-Arg- $\mathrm{NH}_{2}$ and (7-methoxycoumarin-4-yl)acetyl-Arg-Pro-Lys-Pro-Val-GluNva-Trp-Arg-Lys(2,4-dinitrophenyl)- $\mathrm{NH}_{2}$ and substance $\mathrm{P}$ from Bachem, Heidelberg, Germany; Dulbecco's modified Eagle's medium, fetal calf serum, Hank's balanced salt solution, penicillin/ streptomycin, trypsin/EDTA and amphothericin B from Biochrom, Berlin, Germany. All other substances were obtained from Sigma Chemicals, Deisenhofen, Germany.

Gelatinase A and stromelysin-1 were isolated in our laboratory as previously described $(17,18)$. Gelatinase B was purified from buffy coat essentially as described (19). Collagen I was prepared from calf skin according to the method of Miller et al. (20).

\section{Cell culture}

Human synovial tissue obtained from patients with rheumatoid arthritis was enzymatically digested, and adherent cell cultures were established. The synovial cells were maintained in Dulbecco's modified Eagle's medium containing fetal calf serum (volume fraction 0.1 ) until confluency was achieved. According to Firestein et al. (21), in primary cultures of the synovial lining cells after 2 or 3 passages a relative homogenous population of fibroblasts like synoviocytes is left. So in the $3^{\text {rd }}$ and $4^{\text {th }}$ passages, the culture medium was changed to Dulbecco's modified Eagle's medium $2 \mathrm{~g} / 1$ lactalbumin hydrolysate, and the cells were stimulated with substance $P\left(10^{-8} \mathrm{~mol} / \mathrm{l}\right)$ and interleukin- $1 \beta(0.3 \mu \mathrm{mol} / \mathrm{l})$. After $24 \mathrm{~h}$ the media were collected. To overcome the variability of the cell cultures of the different donors as well as the variability within the group of culture flasks of one single donor, the activity increases of the matrix metalloproteinases of a single cell culture dish was always related to the values obtained before stimulation and not to the parallel control cultures.

\section{Enzyme assays}

General matrix metalloproteinase-activities were assayed with the synthetic substrate dinitrophenyl-Pro-Gln-Gly-Ile-Ala-Gly-Gln- $D$ Arg (dinitrophenyl-labelled peptide, $250 \mathrm{mg} / \mathrm{l}$ ) as described by $\mathrm{Ma}$ sui et al. (22) and with the fluorogenic substrate (7-methoxycoumarin-4-yl)acetyl-Pro-Leu-Gly-Leu[3-(2,4-dinitrophenyl)-2,3-diaminopropionyl]-Ala-Arg- $\mathrm{NH}_{2}(25 \mu \mathrm{mol} / \mathrm{l})$ as introduced by Knight et al. (23).

The stromelysin-1 specific fluorogenic substrate (7-methoxycoumarin-4-yl)acetyl-Arg-Pro-Lys-Pro-Val-Glu-Nva-Trp-Arg-Lys (2,4dinitrophenyl)- $\mathrm{NH}_{2}(12.5 \mu \mathrm{mol} / \mathrm{l})$ was employed essentially as described by Nagase et al. (24).

In the three assays $50 \mu \mathrm{l}$ of the medium samples, $5 \mu \mathrm{l} 40 \mathrm{mmol} / \mathrm{l} p$ aminophenylmercury acetate (APMA) in dimethyl sulphoxide and $45 \mu \mathrm{l} 50 \mathrm{mmol} / 1 \mathrm{Tris}-\mathrm{HCl}, \mathrm{pH} 7.0,200 \mathrm{mmol} / \mathrm{l} \mathrm{NaCl}, 5 \mathrm{mmol} / 1$ $\mathrm{CaCl}_{2}, 5 \mu \mathrm{mol} / / \mathrm{ZnCl}_{2}, 0.5 \mathrm{~g} / \mathrm{l} \mathrm{NaN}{ }_{3}$ were incubated with $100 \mu \mathrm{l}$ of the distinct substrate solution.

In the fluorescence assays the activities were continuously monitored in microtitre plates for $90 \mathrm{~min}$ at $25^{\circ} \mathrm{C}$. In the assay with the dinitrophenyl-labelled peptide the reaction was stopped after $5 \mathrm{~h}$ with $0.5 \mathrm{ml} 0.5 \mathrm{~mol} / 1 \mathrm{HCl}$. The hydrolyzed dinitrophenyl-labelled peptide was extracted with acetic ethylester/butanol $(1+0.15$, by vol.), and the absorbance determined at $365 \mathrm{~nm}$.

Collagenase activity was also measured with type I collagen as substrate. Matrix metalloproteinase solutions $(20 \mu \mathrm{l})$ were activated with $2 \mathrm{mmol} / \mathrm{lmersalylic}$ acid and incubated with $20 \mu \mathrm{l} 2 \mathrm{~g} / \mathrm{l}$ collagen I for $20 \mathrm{~h}$ at $20^{\circ} \mathrm{C}$. Degradation of collagen I was analysed by $8 \%$ SDS-PAGE.

To demonstrate the presence of the progelatinase A-TIMP-2 complex, ${ }^{2}$ ) its inhibitory capacity against active gelatinase B was shown. The media were ultrafiltrated at a relative molecular mass cut-off of $M_{\mathrm{r}} 30000$ to eliminate TIMP-1. The gelatinase A-TIMP2-containing fractions were incubated with active gelatinase $\mathrm{B}$ for $30 \mathrm{~min}$ at $37^{\circ} \mathrm{C}$ and the activity of gelatinase B was measured using the dinitrophenyl-labelled peptide (22) as substrate (incubation: $30 \mathrm{~min}, 37^{\circ} \mathrm{C}$ ).

\section{Gelatin zymography}

Twenty (20) $\mu 1$ of culture media were prepared without heating or reduction for sodium dodecyl sulphate-polyacrylamide gel electrophoresis (SDS-PAGE) containing $2 \mathrm{~g} / 1$ gelatin. After electrophoresis the gels were washed twice in $25 \mathrm{~g} / 1$ Triton X-100 in $50 \mathrm{mmol} / 1$ Tris-HCl pH 7.6, $200 \mathrm{mmol} / 1 \mathrm{NaCl}, 5 \mathrm{mmol} / 1 \mathrm{CaCl}_{2}, 5 \mu \mathrm{mol} / \mathrm{l}$ $\mathrm{ZnCl}_{2}, 0.5 \mathrm{~g} / 1 \mathrm{NaN}_{3}$, then they were washed shortly in the same buffer without Triton. The gels were incubated for $6 \mathrm{~h}$ at $37^{\circ} \mathrm{C}$ in the same buffer containing $10 \mathrm{~g} / 1$ Triton X-100. Afterwards they were fixed and stained in Coomassie Brilliant Blue.

\section{Western blot}

Immediately after electrophoresis, proteins were blotted to Immobilon membranes. Immunologic blot analysis was performed using affinity purified polyclonal rabbit anti-human-gelatinase A $(1: 500)$, polyclonal guinea pig anti-rabbit-collagenase $(1: 200)$ and guinea pig anti-rabbit-stromelysin- $1(1: 1000)$. The second antibodies used were goat anti-rabbit-IgG-peroxidase conjugate and rabbit anti-guinea pig-IgG-peroxidase conjugate (both $1: 2000$ ). The blots were developed with aminoethyl carbazole.

\section{Extraction of protein bands after SDS-PAGE}

Sodium dodecylsulphate gel electrophoresis (10\% SDS-PAGE) was performed as generally established. To relate single matrix metalloproteinase activities the respective protein bands were ex-

${ }^{2}$ ) TIMP = Tissue inhibitor of metalloproteinases 
cised from the gel after a very short staining with water soluble Coomassie Brilliant Blue. For protein extraction the sections were placed into separate tubes each containing $200 \mu 150 \mathrm{mmol} / 1$ Tris$\mathrm{HCl}, \mathrm{pH} 7.0 ; 200 \mathrm{mmol} / 1 \mathrm{NaCl}, 5 \mathrm{mmol} / \mathrm{l} \mathrm{CaCl}, 5 \mu \mathrm{mol} / / \mathrm{ZnCl}_{2}$, $0.5 \mathrm{~g} / 1 \mathrm{NaN}_{3}, 10 \mathrm{~g} / 1$ Triton X-100 followed by an overnight incubation at room temperature. Matrix metalloproteinase-activities were determined as described before to obtain a relative pattern of activities.

\section{Results}

\section{Generally}

The total activity of metalloproteinases towards the dinitrophenyl-labelled peptide determined in the culture media of primary synovial fibroblasts as compared to the activities of the single culture dish before stimulation is increased by more than $124 \% 24 \mathrm{~h}$ after application of IL-1 $\beta$. However, the exposure to the neuropeptide substance $\mathrm{P}\left(10^{-8} \mathrm{~mol} / \mathrm{l}\right)$ induces an increase in matrix metalloproteinase activity of about $84 \%$ (fig. 1). Unstimulated cells show a spontaneous augmentation of matrix metalloproteinase activity of about $27 \%$ after changing the medium from fetal calf serum to lactalbumin hydrolysate. In gel electrophoresis (fig. 2) the media of cells treated with substance $P$ show a strikingly different protein pattern compared to that obtained after interleukin-1 stimulation. Indeed, gelatinase $\mathrm{A}$ at $M_{\mathrm{r}}$ 67000 can be seen as a clear protein band after substance $P$ exposure, whereas after interleukin-1 $\beta$ treatment this band is slightly decreased. However, the secretion of collagenase and stromelysin-1 (four bands closely positioned at about $M_{\mathrm{r}} 50000$ ) is barely enhanced after substance $P$ treatment, but appear very pronounced after interleukin-1 treatment.

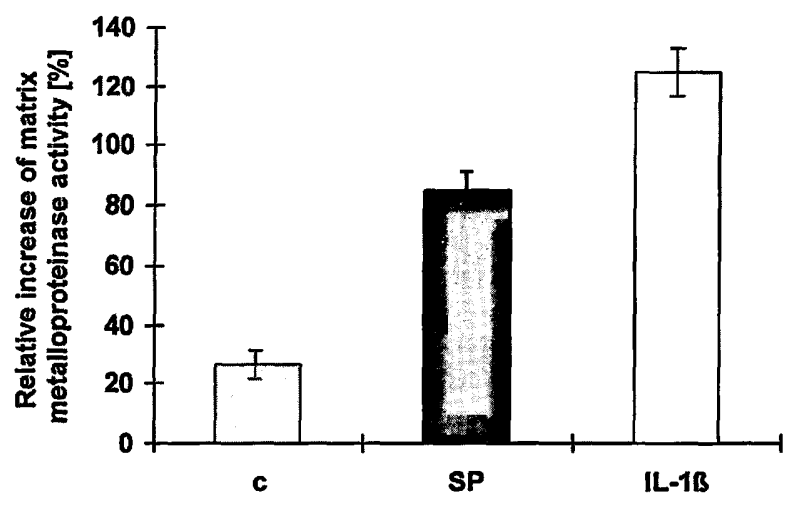

Fig. 1 Relative increase of overall matrix metalloproteinase activity secreted by synovial fibroblasts $24 \mathrm{~h}$ after stimulation with substance $P$ (SP, $10^{-8} \mathrm{~mol} / \mathrm{l}$ ) and interleukin- $1 \beta$ (IL-1 $\beta, 0.3$ $\mu \mathrm{mol} / \mathrm{l})$.

Samples were activated with $2 \mathrm{mmol} / \mathrm{l}$ p-aminophenylmercury acetate. The activity was measured with the dinitrophenyl-labelled peptide after overnight incubation at $37^{\circ} \mathrm{C}$. The activities determined in all media samples before withdrawal of fetal calf serum were defined to be 0 ;

$c=$ parallel control without stimulation, but with change to lactalbumin hydrolysate containing medium.

\section{Gelatinase A-TIMP-2 complex}

The fact that gelatinase $\mathrm{A}$ is the predominant enzyme after substance $P$ treatment, but faints after interleukin-1 exposure is demonstrated by gelatin zymography (fig. 3) and immunoblot analysis (fig. 4c). It is known that human synovial fibroblasts secrete progelatinase A mainly complexed with the tissue inhibitor ${ }^{2}$ ) of metalloproteinases TIMP-2. After activation the whole complex displays gelatinolytic activity, while progelatinase A-TIMP-2 is an inhibitor of other matrix metalloproteinases as well (17). TIMP-2 is visible in gel electrophoresis only after silver staining (not shown). After ultrafiltration the protein fraction greater than $M_{\mathrm{r}} 30000$ of substance $P$ treated media inhibits gelatinase $B$ three times more than the control media.

These results are consistent with the matrix metalloproteinase activities we measured in the extracts of the geleluted protein employing a fluorogenic matrix metallo-

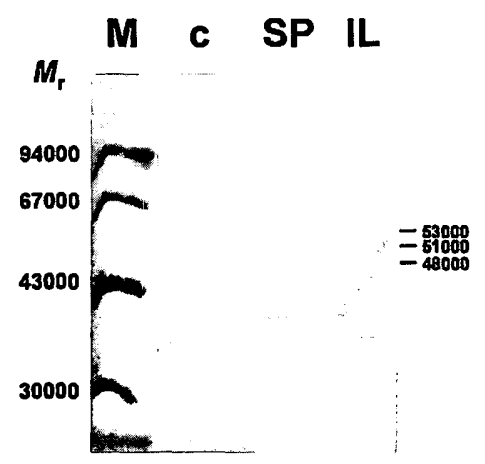

Fig. $210 \%$ SDS polyacrylamide gel electrophoresis of culture media of human synovial fibroblasts without stimulation (control, c) and after stimulation with substance P (SP) or interleukin-1 $\beta$ (IL). Twenty (20) $\mu \mathrm{l}$ of 5 -fold concentrated media were applied to each lane. The gels were run under non-reducing conditions and stained with Coomassie Brilliant Blue.

Lane M: Molecular mass markers $\left(M_{\mathrm{r}}\right)$ : phosphorylase b $(94000)$, bovine serum albumin $(67000)$, ovalbumin $(43000)$, carbonic anhydrase $(30000)$.

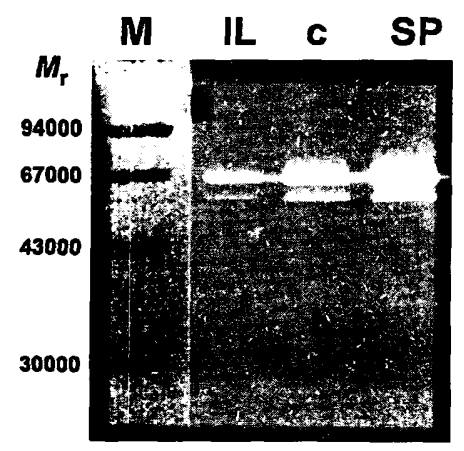

Fig. 3 Zymogram analysis of gelatinase A secreted into culture media by human synovial fibroblasts without stimulation (control, c) and after treatment with interleukin-1 $\beta$ (IL) and substrate P (SP). Medium samples were assayed $24 \mathrm{~h}$ after stimulation. The active $M_{\mathrm{r}} 67000$ form and the further activated $M_{\mathrm{r}} 62000$ form of gelatinase $\mathrm{A}$ are visible.

Lane M: Molecular mass markers $\left(M_{\mathrm{r}}\right)$ : phosphorylase b $(94000)$, bovine serum albumin (67000), ovalbumin (43000), carbonic anhydrase $(30000)$. 


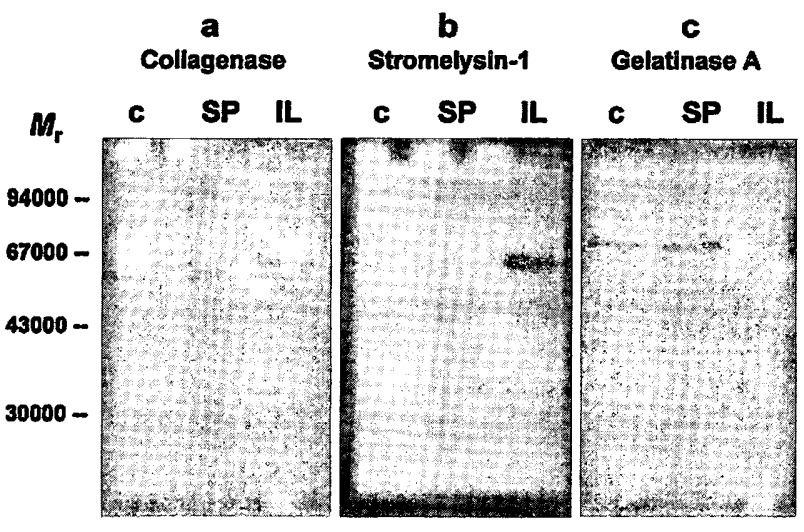

Fig. 4 Immunoblot of culture media of human synovial fibroblasts.

c: control media; SP: after stimulation with substance P; IL: after stimulation with interleukin-1 $\beta$. Blot a was incubated with guinea pig anti-rabbit interstitial collagenase. Blot $b$ was incubated with guinea pig anti-rabbit stromelysin-1. Blot $\mathrm{c}$ was incubated with rabbit anti-human gelatinase $\mathrm{A}$.

proteinase substrate introduced by Knight et al. (23). After substance $\mathrm{P}$ treatment the protein eluted from the band at $M_{\mathrm{r}} 67000$ displays a gelatinolytic activity of $1.13 \mathrm{mU}$ per band, in contrast to $0.74 \mathrm{mU}$ per band in the control. The treatment with interleukin-1 resulted in a significant decrease of the gelatinase activity to 0.06 $\mathrm{mU}$ per band.

\section{Interstitial collagenase}

A typical electrophoretical pattern of media after stimulation with the neuropeptide substance $P$ or the cytokine interleukin- 1 is presented in figure 2 . It is evident that after substance $\mathbf{P}$ exposure the intensities of the protein bands around $M_{\mathrm{r}} 50000$ do not differ significantly from the protein bands seen in the control media. However, interleukin- $1 \beta$ treatment induces a remarkable increase of interstitial collagenase, which is very pronounced in the $M_{\mathrm{r}} 51000$ form of this collagenase.

The collagenase activity of the extracts derived from the gel section was estimated by virtue of cleaving collagen type 1 (fig. 5). An identical observation can be made using either the unstimulated media (lane 2,3 ) or the media after exposure to substance $P$ (lane 4,5 ). The protein extracts of the band at $M_{\mathrm{r}} 53000$ and $M_{\mathrm{r}} 48000$, which represent the latent and active forms of interstitial collagenase both hydrolyse moderately collagen type I. After interleukin-1 treatment the activity of the $M_{\mathrm{r}}$ 53000 collagenase is not different from that observed in the media of substance $P$ treated and control cells (lane 2-5). But an additional and rather broad band seen at $M_{\mathrm{r}} 51000$ as well as the $M_{\mathrm{r}} 48000$ collagenase, which represents only a rather weak band in gel electrophoresis (lane 7,8 ), cleave collagen type I.

Western blot analysis (fig. 4a) of the media shows that anti-collagenase binds predominantly to the triple band of collagenase. In the interleukin- $1 \beta$ stimulated media especially the $M_{\mathrm{r}} 53000$ band is very pronounced (fig. $4 a$, lane 3). After exposure to substance $P$ the three bands are only slightly more distinct (lane 2) than in the control media. The active $M_{\mathrm{r}} 48000$ form seems to be equally recognized by the antibody in all three groups.

\section{Stromelysin-1}

According to Western blot analysis stromelysin-1 seems to be increased only slightly after substance $P$ treatment (fig. 4b, lane 2), but the high rate of secretion after IL1 stimulation is by far not reached (lane 3 ).

Trying to identify the stromelysin-1 band which possibly overlaps with collagenase bands, we extracted four gel slices of $M_{\mathrm{r}} 53000, M_{\mathrm{r}} 51000, M_{\mathrm{r}} 50000$ and $M_{\mathrm{r}} 48000$ from sodium dodecylsulphate gels following water soluble Coomassie staining. Stromelysin-1 could only be detected in media exposed to interleukin-1 at about $M_{\mathrm{r}}$ 50000 by its ability to hydrolyze a specific fluorogenic substrate introduced by Nagase et al. (24). The stromelysin- 1 activity was about $0.05 \pm 0.022 \mathrm{mU} / \mathrm{band}$.

\section{Discussion}

In the present study, we analysed the secretion pattern of the interstitial collagenase (matrix metalloproteinase1), stromelysin-1 (matrix metalloproteinase-3) and gelatinase A (matrix metalloproteinase-2) in culture media of synovial fibroblasts, untreated and treated with the neuropeptide substance $P$ and the cytokine interleukin$1 \beta$.

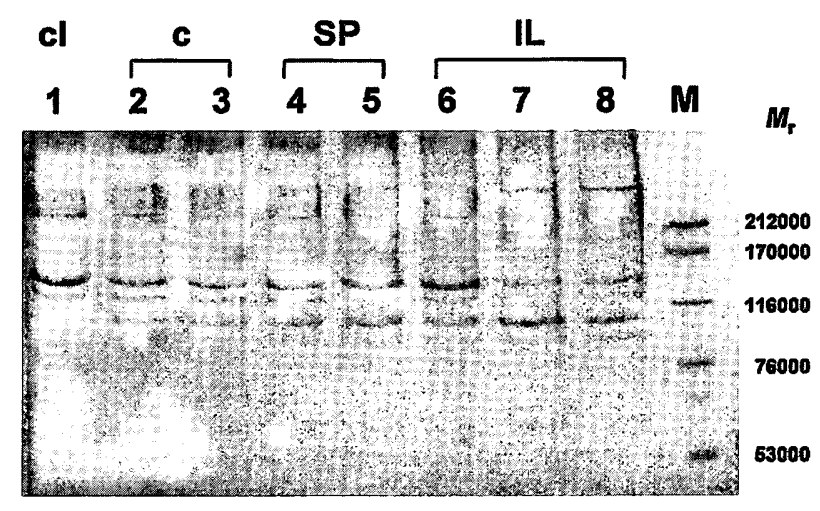

Fig. 5 Collagenolytic activity against collagen type I: After polyacryl amide gel electrophoresis of synovial fibroblast culture media the separated matrix metalloproteinases were excised from the gel, extracted and incubated with collagen type I (cI). Lane 1 shows the collagen type I control, Lane 2 and 3: collagen type I after incubation with $M_{\mathrm{r}} 53000$ and $M_{\mathrm{r}} 48000$ collagenase from the control media (c); Lane 4 and 5: collagen type I after incubation with $M_{\mathrm{r}}$ 53000 and $M_{\mathrm{r}} 48000$ collagenase after substance P-treatment of cells (SP); lane 6-8: collagen type I after incubation with $M_{\mathrm{r}}$ $53000, M_{\mathrm{r}} 51000$ and $M_{\mathrm{r}} 48000$ collagenase as obtained after stimulation of cells with interleukin-1 $\beta$ (IL).

Lane M: Molecular mass markers $\left(M_{\mathrm{r}}\right)$ : myosin $(212000), \alpha_{2}$-macroglobulin $(170000), \quad \beta$-galactosidase $(116000)$, transferrin $(76000)$, glutamic dehydrogenase $(53000)$. 
Although the matrix metalloproteinase activities were measured in the culture media of cells of different donors the activity increases obtained (expressed in \% in relation to the activities before stimulation) were homogenous and the observed differences significant. The donors were not under any steroidal antiinflammatory therapy, but indeed under various other medication and in different stages of the disease. Nevertheless, it can be assumed that at the time of stimulation (after 3 to 4 passages) the cells were no longer exposed to the original inflammatory cytokine milieu, and a relative homogenous population of synovial lining cells in a quiescent state were present (21).

In the gelatin zymography (fig. 3) the media of substance $\mathrm{P}$ treated cells display not only a remarkable increase of the $M_{\mathrm{r}} 67000 \mathrm{form}$, but also of the activated $M_{\mathrm{r}} 62000$ form of gelatinase A. This observation is quite in contrast to the situation seen in the media of interleukin-1 treated cells, where a decrease in gelatinase A activity can be observed. It seems that substance $P$ - if at all - has only a moderate effect on the induction of stromelysin-1 and collagenase secretion, whereas both matrix metallproteinases are predominantly present in the media of cells exposed to interleukin-1 (figs. 2 and 4). Lotz et al. (5) who did not determine the activities of gelatinase and stromelysin-1 separately, found a 5 to 8fold increase in collagenolytic activity against collagen type III. We did not find such a remarkable increase after substance $P$ treatment. The discrepancy may be due to the different assays applied. Moreover, in the assay of Lotz et al. (5) it is not clear, to what extent stromelysin1 and gelatinase $\mathrm{A}$ are involved in the observed degradation of collagen type III.

As shown here the substance $P$ induced increase of the overall matrix metalloproteinase activity $(85 \%)$ towards the dinitrophenyl-labelled peptide is mainly due to enhanced gelatinase A expression.

The selective upregulation of gelatinase $A$ has also been reported for transforming growth factor- $\beta$ (13), but simultaneously collagenase and stromelysin-1 were downregulated. In cultured fibroblasts transforming growth factor- $\beta$ also induces the expression of gelatinase B (13). We definitely did not observe any gelatinase B activity (fig. 3, zymogram) after substance $P$ stimulation. However, collagenase and stromelysin-1 activity were not significantly enhanced.

While the regulation of collagenase and stromelysin-1 gene expression have been extensively investigated, the regulation of gelatinase A gene expression is by far not clear. But it is known that the oncogene families fos and jun are involved in positive as well as in negative regulation of matrix metalloproteinase-expression. Phorbol-12-myristate-13-acetate and the cytokines interleukin- $1 \beta$ and tumour necrosis factor- $\alpha$ as well as trans- forming growth factor- $\beta$ induce $c$-fos gene expression, but finally display opposite effects in matrix metalloproteinase-expression (13). The neuropeptide substance $P$ represents a different type of stimulus which strongly induces gelatinase $\mathrm{A}$ and does not significantly affect collagenase and stromelysin-1 secretion.

Lotz et al. (5) postulated a general increase in total protein synthesis, including collagenase synthesis. Our data indicate that the postulated augmented protein expression - at least within the matrix metalloproteinases was not at all general, but rather significantly shifted mainly to gelatinase A (fig. 2).

Lotz et al. (5) also showed that substance $P$ and interleukin-1 stimulation of fibroblasts occurs through distinct receptors. Substance $P$ is known to act via receptors of the neurokinin-1-type in epithelial cells (25). Oblas et al. (26) report of an substance P binding protein from the heat shock (HSP) 70 family in horse salivary glands. Heat shock substances are among others also known to stimulate matrix metalloproteinase-expression in different cell types (for review see 1.c. (13)). The receptor implicated in the stimulation of synovial fibroblasts has so far not yet been identified.

Tissue responses to the exposure to substances such as lipopolysaccharides or phorbol esters are often amplified by autocrine cytokine expression (15). A significant release of prostaglandin $E_{2}$ and interleukin-1 resulting from substance $P$ treatment of synovial fibroblasts has been observed by several authors $(5,27)$. Cytokine interleukin-1 is known to induce not only matrix metalloproteinase-secretion, but also the expression and secretion of prostaglandin $\mathrm{E}_{2}$ (28). Therefore, one might expect that a prolonged exposure of synovial cells to substance $P$ may lead to an enhanced collagenase and stromelysin-1 secretion via a substance P-induced upregulation of interleukin-1 or prostaglandin $E_{2}$. Treatment of cells for $24 \mathrm{~h}$ was obviously not sufficient to observe this effect. On the other hand it was demonstrated (29) that the interleukin-1 effect on fibroblast collagenase-expression is not dependent on enhanced prostaglandin $\mathrm{E}_{2}$ production, but that both mediators increase collagenase expression by separate regulatory mechanisms $(30,31)$.

The neuropeptide substance $P$ seems to display multiple effects in the inflamed joint. Substance $P$ induces mainly gelatinase A. Apart from its gelatinolytic activity this matrix metalloproteinase has an invasive potency to cells, which may enable them to destroy matrix components. In the state of chronic inflammation and pain this invasive potential may promote the proliferative processes of the synovial fibroblasts, the formation of pannus and its ability to invade the cartilage and to destroy bone. Furthermore, at the same time the neuropeptide 
induces the secretion of cytokines from monocytes, macrophages and synoviocytes which are all present in the inflamed joint $(5,9,29)$ and further enhance the vicious circle of inflammation and tissue destruction.

\section{References}

1. Proud D, Kaplan AP. Kinin formation: mechanisms and role in inflammatory disorders. Annu Rev Immunol 1988; 6:49-83.

2. Matucci-Cerinic M, Partsch G. The contribution of the peripheral nervous system and the neuropeptide network to the development of synovial inflammation. Clin Exp Rheumatol 1992; 10:211-5.

3. Marshall KW, Chin B, Inman RD. Substance $P$ and arthritis: analysis of plasma and synovial fluids. Arthr Rheum 1989; 33:87-90.

4. Matucci-Gerinic $M$. High levels of substance $P$ in rheumatoid arthritis synovial fluid. Lack of substance $P$ production by synoviocytes in vitro. Clin Exp Rheumatol 1991; 9:440-1.

5. Lotz M, Carson DA, Vaughan JH. Substance P activation of rheumatoid synoviocytes: neural pathway in pathogenesis of arthritis. Science 1987; 235:893-5.

6. Kidd BL, Mapp PL, Gibson J, Polak JM, Buckland-Wright JC, Blake DR. A neurogenic mechanism to explain symmetrical synovitis. Lancet 1989; II:1128-30.

7. Gronblad M, Konntinen YT, Korkala O, Liesi P, Hukkanen M, Polak J. Neuropeptides in the synovium of patients with rheumatoid arthritis and osteoarthritis. J Rheumatol 1988; 15:1807-10.

8. Lotz M, Vaughan JH, Carson DA. Effect of neuropeptides on production of inflammatory cytokines by human monocytes. Science 1988; 241:1218-21.

9. Agro A, Stanisz AM. Are lymphocytes a target for substance $P$ modulation in arthritis? Semin Arthritis Rheum 1992; 21:252-8.

10. Hamilton JA, Butler DM, Stanton H. Cytokine interactions promoting DNA synthesis in human synovial fibroblasts. J Rheumatol 1994; 21:797-803.

11. Partsch G, Matucci-Cerinic M, Marabini S, Jantsch S, Pignone A, Cagnoni M. Collagenase synthesis of rheumatoid arthritis synoviocytes: dose dependent stimulation by substance $\mathrm{P}$ and capsaicin. Scand J Rheumatol 1991; 20:98-103.

12. Matrisian LM. The matrix-degrading metalloproteinases. Bio Essays 1992; 14:455-63.

13. Mauviel A. Cytokine regulation of metalloproteinase gene expression. J Cell Biochem 1993; 53:288-95.

14. Martel-Pelletier J, Zafarullah M, Kodama S, Pelletier JP. In vitro effects of IL-1 on the synthesis of metalloproteinases, TIMP, plasminogen activators and inhibitors in human articular cartilage. J Rheumatol 1991: 18 Suppl 27:80-4.

15. Fini ME, Strissel KJ, Girard MT, West Mays J, Rinehart WB. Interleukin- $1 \alpha$ mediates collagenase synthesis stimulated by phorbol 12-myristate 13-acetate. J Biol Chem 1994; 269:11291-8.

16. Van Leeuwen MA, Westra J, Limburg PC, van Riel PLCM, van Rijswijk MH. Interleukin-6 in relation to other proinflammatory cytokines, chemotactic activity and neutrophil activation in rheumatoid synovial fluid. Ann Rheum Dis 1995; $54: 33-8$.

17. Kolkenbrock H, Orgel D, Hecker-Kia A, Noack W, Ulbrich N. The complex between a tissue inhibitor of metalloproteinase (TIMP-2) and $72 \mathrm{kDa}$ progelatinase is a metalloproteinase inhibitor. Eur J Biochem 1991; 198:775-81.

18. Kolkenbrock H, Hecker-Kia A, Orgel D, Huser H, Schröder $\mathrm{W}$, Ulbrich $\mathrm{N}$. Isolation of latent $31 \mathrm{kDa}$ C-truncated stromely-

\section{Acknowledgements}

We thank Oliver Neumann for excellent technical assistance. We would like to thank the Deutsche Forschungsgemeinschaft (UI 93/ 6-1, Zi 465/1-1) for financial support.

sin- 1 and $21 \mathrm{kDa}$ stromelysin-1 from rabbit synovial fibroblasts: an alternative activation pathway for stromelysin-1. Biol Chem Hoppe-Seyler 1994; 375:241 - 7 .

19. Hibbs MS, Hasty KA, Seyer JM, Kang AH, Mainardi CL. Biochemical and immunological characterization of the secreted forms of human neutrophil gelatinase. J Biol Chem 1985; 260:2493-500.

20. Miller EJ, Rhodes RK. Preparation and characterisation of different types of collagen. Meth Enzymol 1982; 82:33-64.

21. Firestein GS. Invasive fibroblast-like synoviocytes in rheumatoid arthritis. Arthritis Rheum 1996; 39:1781-90.

22. Masui Y, Takemoto T, Sakakibara S, Hori H. Synthetic substrates for vertebrate collagenase. Biochem Med 1977; $17: 215-21$.

23. Knight CG, Willenbrock F, Murphy G. A novel coumarin-labelled peptide for sensitive continuous assays of the matrix metalloproteinases. FEBS Lett 1992; 296:263-6.

24. Nagase A, Fields CG, Fields GB. Design and characterization of a fluorogenic substrate selectively hydrolysed by stromelysin-1 (matrix metalloproteinase 3). J Biol Chem 1994; 269:20952-7.

25. Ziche M, Morbidelli L, Geppetti P, Maggi CA, Dolara P. Substance $P$ induces migration of capillary endothelial cells: a novel NK-1 selective receptor mediated activity. Life Sci 1991; 48:PL 7-11.

26. Oblas B, Boyd ND, Luber-Narod J, Reyes VE, Leeman SE. Isolation and identification of a polypeptide in the HSP 70 family that binds substance P. Biochem Biophys Res Commun $1990 ; 166: 978-83$.

27. Kimball ES, Persico FJ, Vaught JL. Substance P, neurokinin $\mathrm{A}$, and neurokinin $\mathrm{B}$ induce generation of IL-1-like activity in P388D1 cells. J Immunol 1988; 141:3564-9.

28. Dayer JM, de Rochemontiex B, Burrus B, Demczuk S, Dinarello CA. Human recombinant interleukin-1 stimulates collagenase and prostaglandin $D_{2}$ production by human synovial cells. J Clin Invest 1986; 77:645-8.

29. Mauviel A, Halcin C, Vasiloudes P, Parks WC, Kurkinen M, Uitto J. Uncoordinate regulation of collagenase, stromelysin1 , and tissue inhibitor of metalloproteinases genes by prostaglandin $\mathrm{E}_{2}$ : selective enhancement of collagenase gene expression in human dermal fibroblasts in culture. J Cell Biochem 1994; 54:465-72.

30. Frisch SM, Clark EJ, Werb Z. Coordinate regulation of stromelysin- 1 and collagenase genes determined with cDNA probes. Proc Natl Acad Sci USA 1987; 84:2600-4.

31. MacNaul KL, Charttrain N, Lark M, Tocci MJ, Hutchison NI. Discoordinate expression of stromelysin-1, collagenase and tissue inhibitor of metalloproteinases- 1 in rheumatoid human synovial fibroblasts: synergistic effects of interleukin- 1 and tumor necrosis factor $\alpha$ on stromelysin-1 expression. J Biol Chem 1990; 265:17238-45.

\section{Received March 24/June 13, 1997}

Corresponding author: Prof. Dr. N. Ulbrich, Universitätsklinikum Charité der Humboldt Universität Berlin, Medizinische Klinik III, Tucholskystraße 2, D-10117 Berlin, Germany 